\author{
Dominique D. Benoit \\ Marcio Soares \\ Elie Azoulay
}

\section{Has survival increased in cancer patients admitted to the ICU? We are not sure}

Received: 29 August 2014

Accepted: 31 August 2014

Published online: 13 September 2014

(C) Springer-Verlag Berlin Heidelberg and ESICM 2014

\section{D. Benoit $(\square)$}

Medical Unit, Department of Intensive Care, Ghent University Hospital, De Pintelaan 185, 12K12IB, 9000 Ghent, Belgium

e-mail: dominique.benoit@ugent.be

M. Soares

D’Or Institute for Research and Education, Rio De Janeiro, Brazil

E. Azoulay

Service de Reanimation Medicale, Hopital Saint-Louis et Universite Paris 7, Assistance Publique Hôpitaux de Paris, Paris, France

We are committed to providing a balanced answer on the reality of improved survival in critically ill patients with cancer. By defending the pro viewpoint, Mokart et al. [1] may be right in claiming that survival in cancer patients in general and more particularly in those with hematological malignancies has increased over the past decade. As recently reported in a prospective study including more than 1,000 hematological patients admitted to 18 ICUs from a French-Belgian network [2], overall mortality was $50 \%$, but more important were mortality rates in the sickest subgroups: $60 \%$ in the case of either one vital organ failure (need for ventilation, vasopressor, or dialysis) or two vital organ failures if reversible within 7 days. Congruently to this finding, mortality rates in severe sepsis and septic shock (the most common complications in this population [3-6]) were 34 and $46 \%$, respectively, approaching the figures in the non-cancer population. More recently, a large multicenter study using data from the Dutch National Intensive Care Evaluation (NICE) database published in this journal indicated that 60-day mortality in patients with hematological malignancies was similar to that in solid cancer patients and also in patients with other more classical severe comorbidities such as chronic heart failure, liver cirrhosis, and chronic pulmonary obstructive disease (COPD) [7]. In other words, triage decisions solely based on the type of underlying comorbidity is becoming obsolete. By defending the con viewpoint, Pène et al. [8] somewhat attenuates this optimism by focusing on the fact that current survival rates are still based on studies performed in heterogeneous populations coming from different centers with different experiences and cultures. Therefore, it seems naïve to recommend broad ICU admission policies or full code status for any patient with cancer and acute organ dysfunction. Strikingly, Pène et al. also shrewdly claim that for the same reasons, routine denial of cancer patients carrying one or several poor prognostic factors would be inappropriate as none of those are specific enough to predict non-beneficial care. At the end of the day, the question remains how we can move forward at the bedside to integrate these results into a genuine decision-making process so as to maintain or even improve long-term outcome in these patients without only prolonging the dying process? Indeed, the reality of physical and emotional suffering of critically ill cancer patients [9] and their relatives [10] cannot remain unrecognized.

Mokart et al. [1] ascribe recent survival benefits mainly to earlier and better supportive care provided to a more selected patient population with less comorbidities and a better performance status. It is true that ICU admission within $24 \mathrm{~h}$ of hospital referral has been associated with improved outcome [11]. The complex relationship between time to ICU admission and mortality has been recently investigated in a study published in this journal 
[12]. Herein, when medical intervention occurred within $1.6 \mathrm{~h}$ of the first physiological derangement, mortality was about $30 \%$, increasing to 55 and $80 \%$ when medical intervention occurred between 1.6 and $4.7 \mathrm{~h}$, and later than $4.7 \mathrm{~h}$, respectively. These findings may be even more relevant in the case of acute respiratory failure or septic shock where mortality varies between 34 and $50 \%$ in highly skilled centers $[2-6,13]$ and 66 and $68 \%$ in general ICUs [14, 15].

Interestingly, both Mokart et al. [1] and Pène et al. [8] highlight that we need to learn how to make appropriate triage decisions taking into account the burden of aggressive intensive care, expected short-term outcomes, cancer outcomes, and long-term outcomes. This requires, however, much more than pure medical skills or scientific knowledge.

The ICU can in some countries be used to provide palliative interventions [16] or non-ICU care [17]. Therefore, the goals of care are clear and patient management can easily be communicated to every stakeholder. Otherwise, clinicians managing patients with cancer have to make decisions of full code ICU management or ICU trial being aware that prognostic uncertainty is the rule [18] and the decision to admit or not is based on contextual criteria. That we should first explore the preferences and/or expertise of all parties involved is rather straightforward. The challenge is then to communicate using words that both provide honest and easy-to-understand information, and at the same time empower every stakeholder to voice concerns and express different experience, offer unexpected options or sound alternatives [18]. Good leadership implies implicitly that we should dare to take decisions more closely in tune with our senses and emotions [19]. Both the current scientific evidence enumerated in this pro-con debate and a certain degree of emotional contamination will be mandatory if we want to effectively anticipate the potentially harmful side effects of inappropriate decisions (Table 1). In daily practice otherwise, discussions are not patient-centered enough and too often turn into a power struggle between healthcare workers. Routinely neglecting the heart of our mission, avoiding discussions and debate, and pursuing inappropriate life-sustaining treatments in patients who will not benefit are exactly what we should not do. Conducting an ICU trial remains a delicate task in which communication and shared discussions and decisions are the key for providing optimal care. Unless supported by objective arguments and well communicated to the relatives and the team, such "wait and see" policy is common $[18,20]$, but may be unfair given the detrimental effects on the patients, relatives, healthcare providers, and society [21].

In summary, we are not completely sure whether survival actually increased in critically ill cancer patients, mostly because there is a risk that patients who were dying in the 1980s and 1990s would no longer be referred to the ICU by hematologists and oncologists, and because no data are available on these aspects. Other possible explanations for this improvement are provided in Fig. 1. Still, we want to see the pro arguments for making the decision to admit patients to the ICU, and take into account the con arguments when after several days patients show no improvement, or maybe deterioration [22]. After an ICU trial, every decision needs to be made after a careful and individual evaluation of the short-term chances of survival, long-term cancer outcomes, and long-term outcomes of organ dysfunction [22]. Then, communication with the relatives and the ICU team must balance the dismal chances for long-term survival and prolonging a painful dying process. Improving decisionmaking and enhancing intra- and interdisciplinary communication and collaboration remain the best way to make a decision in a context of uncertainty, and then adapt the therapeutic project to the patient's evolution. Widely opening the doors of ICU to cancer patients should not be a way to avoid providing non-beneficial
Table 1 From scientific evidence to the bedside: 10 most relevant things intensivists should keep in mind during triage decisions in cancer patients
1. In cancer patients admitted to the ICU, characteristics of the malignancy are no longer associated with short-term mortality

2. Classic predictors of mortality (i.e., neutropenia, autologous BMT, physiologic scores) are not relevant anymore

3. Current mortality in specialized centers is $60 \%$ in the case of one organ failure (need for ventilation, vasopressor, or dialysis) or two organ failures if reversible in less than 7 days

4. Current mortality of severe sepsis and septic shock in highly skilled centers is 30-40\% in the case of non-pulmonary origin and 50-60\% in the case of pulmonary origin in contrast to more than $65 \%$ overall in general ICUs

5. Delays in ICU referral and admission are associated with increased mortality

6. Intensivists are usually overpessimistic regarding short- and long-term outcomes

7. Hemato-oncologists are overoptimistic regarding short- and long-term outcomes

8. Postponing EOL decisions increases the physical and emotional burden of patients and relatives

9. Triage and EOL decisions are an inherent part of an intensivist's duties

10. Prognostic uncertainty is the rule, but we can improve outcome prediction by sharing decisions with all stakeholders inside and outside the team and by taking decisions more closely in tune with our senses and emotions

$I C U$ intensive care unit, BMT bone-marrow transplant, $E O L$ end-of-life 


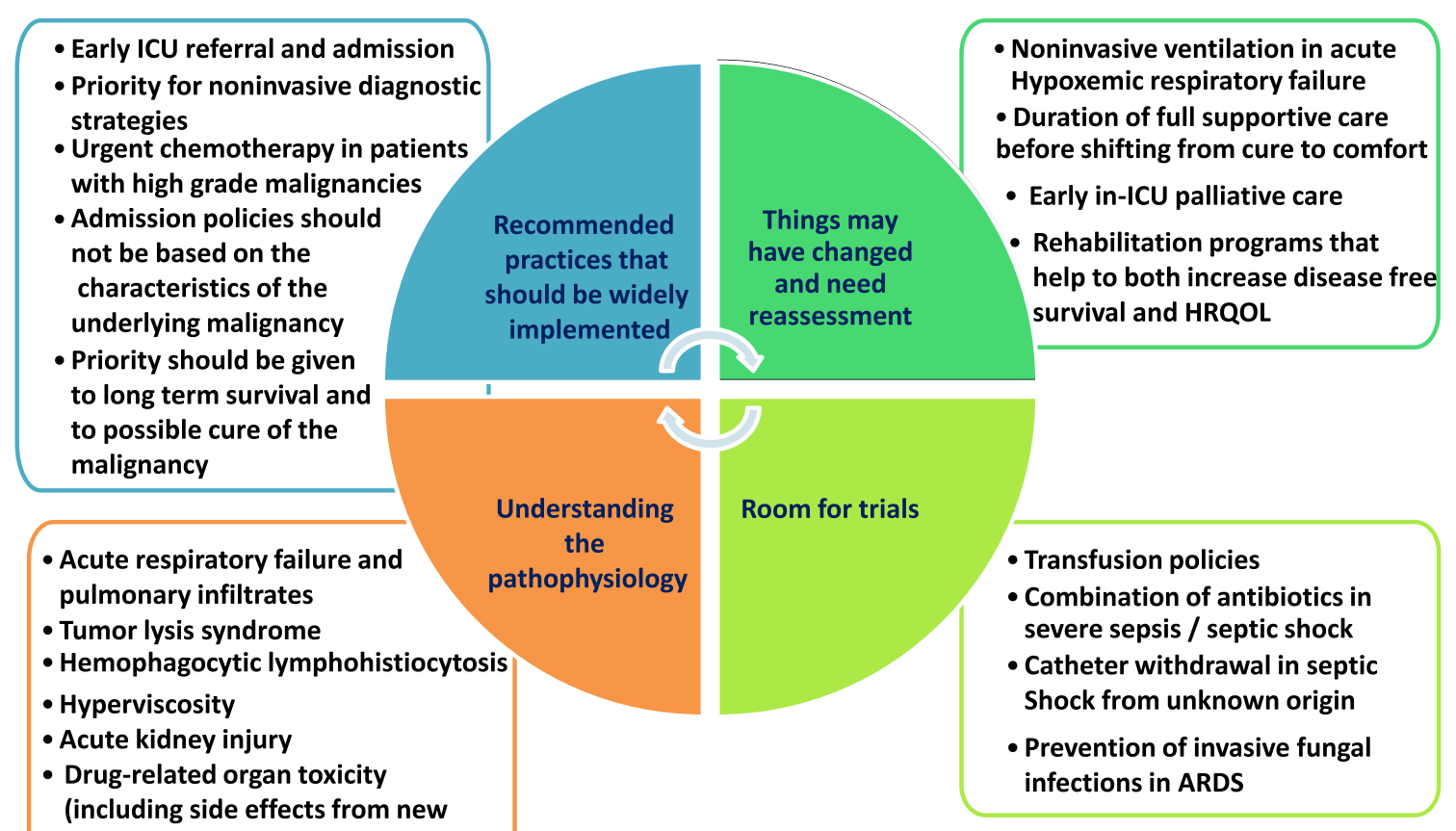

Fig. 1 Possible explanations for the reported increased survival in critically ill cancer patients

care as it will ultimately result in making more decisions of withholding and withdrawing life support, sometimes in a more conflicting atmosphere and after having provided inappropriate care.
Acknowledgments DB received a senior clinical investigator grant from the Research Foundation of Flanders, Belgium (1800513N).

\section{References}

1. Mokart D, Pastores SM, Darmon M (2014) Has survival increased in cancer admitted to the ICU? Yes. Intensive Care Med. doi:

$$
\text { 10.1007/s00134-014-3433-2 }
$$

2. Azoulay E, Mokart D, Benoit D, Pène F, Lambert J, Kouachet A, Mayaux J, Vincent F, Nuyuanga M, Bruneel F, Laisne LM, Rabbat A, Lebert C, Perez P, Chaize M, Renault A, Meert AP, Benoit D, Hamidfar R, Jourdain M, Darmon M, Schlemmer B, Chevret S, Lemiale V (2013) Outcomes of critically ill patients with hematologic malignancies: prospective multicenter data from France and Belgium-a groupe de recherche respiratoire en réanimation onco-hématologique study. J Clin Oncol 31:2810-2818

3. Benoit D, Depuydt P, Peleman R, Offner F, Vandewoude K, Vogelaers D, Blot S, Noens L, Colardyn F, Decruyenaere J (2005) Documented and clinically suspected bacterial infection precipitating ICU admission in severely ill patients with hematological malignancies: impact on outcome. Intensive Care Med 31:934-942

4. Vandijck D, Benoit D, Depuydt P, Offner F, Blot S, Vantilborgh A, Nollet J, Steel E, Noens L, Decruyenaere J (2008) Impact of recent chemotherapy on outcome in severe sepsis and septic shock patients with hematological malignancies. Intensive Care Med 34:847-855

5. Pène F, Percheron S, Lemiale V, Viallon V, Claessens YE, Marqué S, Charpentier J, Angus DC, Cariou A, Chiche JD, Mira JP (2008) Temporal changes in management and outcome of septic shock in patients with malignancies in the intensive care unit. Crit Care Med 36:690-696

6. Zuber B, Thi-Chien T, Aegerter P, Grimaldi D, Charpentier J, Guidet B, Mira JP, Pène F, CUB-Réa Network (2012) Impact of case volume on survival of septic shock in patients with malignancies. Crit Care Med 40:55-62
7. van Vliet M, Verburg IWM, van den Boogaard M, de Keizer NF, Peek N, Blijlevens NMA, Pickkers P (2014) Trends in admission prevalence, illness severity and survival of haematological patients in Dutch intensive care units. Intensive Care Med 40(9):1275-1284. doi:10.1007/s00134-014-3373-x

8. Pène F, Salluh J, Staundinger T (2014) Has survival increased in cancer admitted to the ICU? No. Intensive Care Med. doi:10.1007/s00134-014-3412-7

9. Nelson JE, Meier DE, Oei EJ, Nierman DM, Senzel RS, Manfredi PL, Davis SM, Morrison RS (2001) Self-reported symptom experience of critically cancer patients receiving intensive care. Crit Care Med 29:277-282

10. Fumis RR, Deheinzelin D (2009) Family members of critically ill cancer patients: assessing the symptoms of anxiety and depression. Intensive Care Med 35:899-902 
11. Mokart D, Lambert J, Schnell D, Fouché L, Rabbat A, Kouatchet A, Lemiale V, Vincent F, Lengliné E, Bruneel F, Pene F, Chevret S, Azoulay E (2013) Delayed intensive care unit admission is associated with increased mortality in patients with cancer with acute respiratory failure. Leuk Lymphoma 54:1724-1729

12. Song JU, Suh GY, Park HY, Lim SY, Han SG, Kang YR, Kwon OJ, Woo S, Jeon K (2012) Early intervention on the outcomes in critically ill cancer patients admitted to intensive care units. Intensive Care Med 38(9):1505-1513

13. Lecuyer L, Chevret S, Guidet B, Aegerter P, Martel P, Schlemmer B, Azoulay E (2008) Case volume and mortality in haematological patients with acute respiratory failure. Intensive Care Med 32:748-754

14. Taccone FS, Artigas AA, Sprung CL, Moreno R, Sakr Y, Vincent JL (2009) Characteristics and outcomes of cancer patients in European ICUs. Crit Care 13:R15
15. Hampshire PA, Welch CA, McGrossan LA, Francis K, Harrison D (2009) Admission factors associated with mortality in patients with haematological malignancy admitted to UK adult general critical care units: a secondary analysis of the ICNARC Casemix Program Database. Crit Care 13:R137

16. Azoulay E, Kouatchet A, Jaber S, Lambert J, Meziani F, Schmidt M, Schnell D, Mortaza S, Conseil M, Tchenio X, Herbecq P, Andrivet P, Guerot E, Lafabrie A, Perbet S, Camous L, Janssen-Langenstein R, Collet F, Messika J, Legriel S, Fabre X, Guisset O, Touati S, Kilani S, Alves M, Mercat A, Similowski T, Papazian L, Meert AP, Chevret S, Schlemmer B, Brochard L, Demoule A (2013) Noninvasive mechanical ventilation in patients having declined tracheal intubation. Intensive Care Med 39:292-301

17. Soares M, Azoulay E (2009) Critical management of lung cancer patients to prolong life without prolonging dying. Intensive Care Med 35:2012-2014
18. Piers R, Azoulay E, Ricou B, Dekeyser Ganz F, Max A, Michalsen A, Azevedo Maia P, Owczuk R, Rubulotta F, Meert AP, Reyners A, Decruyenaere J, Benoit D, Appropricus Study Group of the Ethics Section of the European Society of Intensive Care Medicine (2014) Inappropriate care in European ICUs. Confronting views from nurses and junior and senior physicians. Chest 146:267-275

19. Goleman D (1998) What makes a leader? Harv Bus Rev 76:93-102

20. Lind R, Lorem GF, Nortvedt P, Hevroy O (2011) Family members' experiences of "wait and see" as communication strategy in end-of-life decisions. Intensive Care Med 37:1143-1150

21. Kompanje E, Piers R, Benoit D (2013) Causes and consequences of disproportionate care in intensive care medicine. Curr Opin Crit Care 19:630-635

22. Azoulay E, Soares M, Darmon M, Benoit D, Pastores S, Afessa B (2011) Intensive care of the cancer patient: recent achievements and remaining challenges. Ann Intensive Care 1:5 